\title{
Overlap Between Postprandial Distress and Epigastric Pain Syndromes in Functional Dyspepsia: Its Implications for Research and Clinical Practice
}

\author{
(Am J Gastroenterol 2013;108:767-774)
}

\section{Cheol Min Shin}

Department of Internal Medicine, Seoul National University Bundang Hospital, Seoungnam, Gyeonggi-do, Korea

\section{Summary}

The Rome criteria have been the most widely used criteria for defining dyspepsia. The Rome III criteria have divided functional dyspepsia into postprandial distress syndrome (PDS), characterized by postprandial fullness and early satiation, and epigastric pain syndrome (EPS), characterized by epigastric pain or burning. ${ }^{1}$ PDS and EPS are thought to have different pathophysiology, so these 2 syndromes might have different responses to medication, allowing a more rational approach to drug discovery and development.

In the present study, Vakil et $\mathrm{al}^{2}$ evaluated the Rome III criteria for functional dyspepsia taking into consideration of the degree of symptom overlap between the 2 subtypes, PDS and EPS. In addition, the proportion of patients with gastroesophageal reflux disease (GERD) who met the criteria for PDS and/or EPS was also evaluated to determine if these subtypes have value in separating GERD and functional dyspepsia in clinical practice.

Primary care patients with one or more upper gastrointestinal symptoms at least twice a week for a month or longer were enrolled and underwent esophageal endoscopy and 24-hour
pH-metry. GERD was defined as the presence of at least one of the following: reflux esophagitis, pathological esophageal acid exposure, and positive symptom association probability $\geq 95 \%$ for association of symptoms with acid reflux. Functional dyspepsia was defined by the absence of GERD and peptic ulcer disease on investigation, and PDS and/or EPS were diagnosed according to the Rome III criteria.

Of the 336 study participants, 9 had peptic ulcer disease and were excluded from the study. One hundred and eighty-nine patients were diagnosed with GERD and 159 (84\%) of them also met the criteria for PDS and/or EPS: 36 (19\%) had PDS alone, $42(22 \%)$ had EPS alone and $81(43 \%)$ met the criteria for both PDS and EPS. The remaining 138 patients had upper gastrointestinal symptoms with normal endoscopy, pH-metry, and symptom association probability results, consistent with the presence of functional dyspepsia. Of these patients, 130 (94\%) met the criteria for PDS and/or EPS: 13 (10\%) had PDS alone, 31 (24\%) had EPS alone, and 86 (66\%) had both PDS and EPS. Heartburn and/or regurgitation were the predominant symptoms (most or second most bothersome symptoms reported on physician-administered symptom assessment) in 90 (57\%) of 159 GERD patients with concomitant PDS and/or EPS, and in 39

Received: June 12, 2013 Revised: June 21, 2013 Accepted: June 21, 2013

(c) This is an Open Access article distributed under the terms of the Creative Commons Attribution Non-Commercial License (http://creativecommons. org/licenses/by-nc/3.0) which permits unrestricted non-commercial use, distribution, and reproduction in any medium, provided the original work is properly cited.

*Correspondence: Cheol Min Shin, MD

Department of Internal Medicine, Seoul National University Bundang Hospital, 173beon-gil, 82, Gumi-ro, Bundang-gu, Seongnam, Gyeonggi-do 463-707, Korea

Financial support: None.

Tel: +82-31-787-7009, Fax: +82-31-787-4051, E-mail: scm6md@gmail.com

Conflicts of interest: None. 
(30\%) of 130 functional dyspepsia patients with PDS and/or EPS $(P<0.0001)$. In multivariate analysis, PDS is not predictive of functional dyspepsia vs. GERD (OR, 1.120; 95\% CI, $0.657-1.911)$; EPS is a weak predictor of functional dyspepsia (OR 2.910; 95\% CI, 1.596-5.306). In summary, there was considerable overlap between PDS and EPS in patients with functional dyspepsia. The distinction of functional dyspepsia into the subgroups of PDS and EPS may not be effective in clinical trials or clinical practice. New strategies are required for the classification of functional dyspepsia.

\section{Comment}

The Rome III criteria for functional dyspepsia recognize 2 distinct subgroups of PDS and EPS. This classification is supported by accumulated pathophysiological and epidemiological studies. That is, PDS appears to be associated with impaired gastric accommodation and increased duodenal eosinophil counts compared to EPS. ${ }^{3-5}$ Its therapeutic implication is, however, yet to be established well. Disappointingly, studies on antisecretory therapy or Helicobacter pylori eradication failed to demonstrate differential responsiveness between PDS and EPS groups in functional dyspepsia. ${ }^{6-8}$ One exception is acotiamide (Z-338 or YM443), an acetylcholinesterase inhibitor, which enhances gastric emptying and gastric accommodation. ${ }^{9}$ According to the clinical trials, this drug improves postprandial fullness and early satiation but it seems not to be effective in relieving epigastric pain, which implies that acotiamide may be effective in patients with PDS, not those with EPS. ${ }^{10}$ In addition, fundic relaxant drugs including 5-hydroxytryptamine $1 \mathrm{~A}$ agonists might be an appropriate therapeutic option for patients with PDS. ${ }^{11}$ Current therapeutic option for functional dyspepsia remains unsatisfactory; however, to categorize patient's symptoms into PDS or EPS might assist in determining the most appropriate initial therapy. ${ }^{12}$

In this study, most patients with functional dyspepsia who met Rome III criteria for PDS also met those for EPS and vice versa. The authors concluded that subgrouping of functional dyspepsia into PDS and EPS may be ineffective. In fact, a number of studies from different part of the world have evaluated whether there is considerable overlap of PDS and EPS in functional dyspepsia. According to a recent review, several studies in the general population from US and Europe have shown a good separation into the subgroups of PDS and EPS, but other studies in patients seeking medical care for their dyspeptic symptoms have reported major overlap between the 2 subgroups. ${ }^{13}$ In the Vakil study, EPS was more prevalent than PDS (24\% vs. $10 \%)$. However, a community study from Korea has reported that the proportions of PDS, EPS and overlap were 47\%, 26\% and 27\%, respectively ${ }^{14}$; another Korean study in patients who visited primary clinics or tertiary care hospitals has reported that PDS (74.4\%) outnumbered EPS (5.0\%) in the subtypes of functional dyspepsia and that the overlap of the 2 subtypes was minimal $(2.2 \%) .{ }^{15}$ More cross-cultural studies using the Rome III criteria are necessary in this issue.

Another issue is the overlap that exists between functional dyspepsia and GERD. The presence of heartburn and/or regurgitation does not differentiate GERD from functional dyspepsia. In the present study, although heartburn and/or regurgitation as a predominant symptom were more frequent in GERD than in functional dyspepsia ( $57 \%$ vs. $30 \%, P<0.0001$ ), it also occurred frequently in functional dyspepsia. Of importance is that heartburn or regurgitation occurs frequently in functional dyspepsia even after objective GERD has been meticulously excluded by endoscopy (no esophagitis) and 24-hour esophageal $\mathrm{pH}$ monitoring testing (normal esophageal acid exposure and negative symptom reflux association).

Ambulatory intraesophageal $\mathrm{pH}$ monitoring is regarded as a gold standard test for GERD diagnosis, but there are limitations and unsolved issues regarding its diagnostic accuracy and absolute threshold value that reliably identifies GERD patients. Response to proton pump inhibitors was not evaluated in the present study. If a patient has burning retrosternal discomfort or pain (heartburn) but there is no evidence of objective GERD in endoscopy and 24-hour pH-metry and an unsatisfactory response to proton pump inhibitors, then the diagnosis according to the Rome III criteria will be functional heartburn. ${ }^{16}$ It has been reported that the prevalence of dyspeptic symptoms (i.e., postprandial fullness, bloating, nausea and early satiety) was higher among patients with functional heartburn. ${ }^{17}$ Heartburn and dyspepsia may be part of one disease complex. According to the Rome III criteria, it is recommend that any overlap of GERD with functional dyspepsia needs to be carefully considered in clinical practice and experimental trials. ${ }^{1}$ However, excluding all patients with any heartburn or regurgitation from the diagnosis of functional dyspepsia is neither reasonable nor possible. These symptoms would rather be considered as part of the dyspeptic symptoms complex. Further research is required into dyspepsia subgroups, and the Rome III criteria may need to be revised. 


\section{References}

1. Tack J, Talley NJ, Camilleri M, et al. Functional gastroduodenal disorders. Gastroenterology 2006;130:1466-1479.

2. Vakil N, Halling K, Ohlsson L, Wernersson B. Symptom overlap between postprandial distress and epigastric pain syndromes of the Rome III dyspepsia classification. Am J Gastroenterol 2013;108: 767-774.

3. Futagami S, Shindo T, Kawagoe T, et al. Migration of eosinophils and CCR2-/CD68-double positive cells into the duodenal mucosa of patients with postinfectious functional dyspepsia. Am J Gastroenterol 2010;105:1835-1842.

4. Shindo T, Futagami S, Hiratsuka T, et al. Comparison of gastric emptying and plasma ghrelin levels in patients with functional dyspepsia and non-erosive reflux disease. Digestion 2009;79:65-72.

5. Talley NJ, Walker MM, Aro P, et al. Non-ulcer dyspepsia and duodenal eosinophilia: an adult endoscopic population-based case-control study. Clin Gastroenterol Hepatol 2007;5:1175-1183.

6. Futagami S, Shimpuku M, Song JM, et al. Nizatidine improves clinical symptoms and gastric emptying in patients with functional dyspepsia accompanied by impaired gastric emptying. Digestion 2012;86:114-121.

7. Hsu YC, Liou JM, Yang TH, et al. Proton pump inhibitor versus prokinetic therapy in patients with functional dyspepsia: is therapeutic response predicted by Rome III subgroups? J Gastroenterol 2011;46:183-190.
8. Mazzoleni LE, Sander GB, Francesconi CF, et al. Helicobacter pylori eradication in functional dyspepsia: HEROES trial. Arch Intern Med 2011;171:1929-1936.

9. Tack J, Janssen P. Acotiamide (Z-338, YM443), a new drug for the treatment of functional dyspepsia. Expert Opin Investig Drugs 2011;20:701-712.

10. Matsueda K, Hongo M, Tack J, Saito Y, Kato H. A placebo-controlled trial of acotiamide for meal-related symptoms of functional dyspepsia. Gut 2012;61:821-828.

11. Tack J, Janssen P, Masaoka T, Farré R, Van Oudenhove L. Efficacy of buspirone, a fundus-relaxing drug, in patients with functional dyspepsia. Clin Gastroenterol Hepatol 2012;10:1239-1245.

12. Camilleri M, Stanghellini V. Current management strategies and emerging treatments for functional dyspepsia. Nat Rev Gastroenterol Hepatol 2013;10:320.

13. Tack J, Talley NJ. Functional dyspepsia - symptoms, definitions and validity of the Rome III criteria. Nat Rev Gastroenterol Hepatol 2013;10:134-141.

14. Park H. Functional gastrointestinal disorders and overlap syndrome in Korea. J Gastroenterol Hepatol 2011;26(suppl 3):12-14.

15. Park JM, Choi MG, Cho YK, et al. Functional gastrointestinal disorders diagnosed by Rome III questionnaire in Korea. J Neurogastroenterol Motil 2011;17:279-286.

16. Galmiche JP, Clouse RE, Bálint A, et al. Functional esophageal disorders. Gastroenterology 2006;130:1459-1465.

17. Savarino E, Pohl D, Zentilin P, et al. Functional heartburn has more in common with functional dyspepsia than with non-erosive reflux disease. Gut 2009;58:1185-1191. 